\title{
Short Essay
}

\section{Pain medicine and palliative care as an alternative to euthanasia in end-of-life cancer care}

\author{
Michael ERdek \\ Johns Hopkins University, USA
}

There exists support for euthanasia or physician-assisted suicide (PAS) in cases of terminal cancer. One of the premises for this approach is the goal of the alleviation of suffering. Do current means of pain control in the greater overall setting of palliative care serve as a desirable alternative? A contrast comparison may be drawn between the above approaches using both theological and medical sources to show that the enlightened use of both interventional and non-interventional pain medicine approaches in an integrated palliative care setting are a theologically grounded and medically feasible alternative to euthanasia or PAS in this population.

Lay summary: Patients suffering from terminal cancer often have pain. Some have advocated euthanasia or physician-assisted suicide as a potential way of alleviating this suffering. Further examination of this topic, however, shows this approach may be essentially utilitarian and fail to consider the inherent value of human life. There has been significant development in recent years in the fields of pain medicine and palliative care, which afford alternate means of addressing suffering in this patient population.

Keywords: Palliative care, Euthanasia, Physician-assisted suicide, Pain medicine, Cancer pain, Terminal illness

\section{INTRODUCTION}

For the purposes of this paper the author will here accept the definitions offered by Gail A. Van Norman of euthanasia as the "intentional termination of life by active administration of lethal means by a physician to a patient requesting it," and physician-assisted suicide (PAS) as

intentional medical aid by a physician at the explicit request of the patient, to enable the patient to terminate his or her own life. (Van Norman 2014, 178)

Approximately 70 percent of Americans support PAS and 58 percent support euthanasia for the terminally ill with support even higher in Europe, yet there remains strong physician opposition to both PAS and euthanasia, particularly in the U.S. and Britain (Van Norman 2014, 178).

\section{Euthanasia and Physician-Assisted Suicide}

Numerous factors play into the request for euthanasia or PAS issued by patients suffering from terminal disease, both malignant and non-malignant. Suffering without prospect for improvement has been deemed the most important of these reasons, and the presence of pain itself was found to be a major factor in over one-third (44 percent) of euthanasia requests (Van Wesemael et al. 2011, 730). Another study of an end-of-life primary- 
care cancer population yielded that the most common symptoms considered by the relevant patient population to be unbearable were pain, loss of control over one's life, and fear of future suffering (Ruijs et al. 2013, 1). Thus it is interesting to note that two of the most common concerns in end-of-life cancer-care patients are not existing symptoms or limitations, but rather issues of control and of fear.

An integral component of providing quality care for terminal-cancer patients is establishing communication about impending death. Cancer patients make up a significant majority of patients who request PAS, 75 percent in the Netherlands and 79 percent in Oregon (Battin 2004, 2481). Due to the issues mentioned previously, is the request then for PAS simply an effort to re-create autonomy in a fearful population which has lost control? Daniel Callahan of the Hastings Center raises the question, "Why does suicide endow a death with dignity? Does dignity depend upon control?" and implies that PAS is in fact a "medicalization of autonomy" (Callahan 2008, 32). This sense of such acts being a sort of perversion of medicine is echoed by Broeckaert, who claims, "knowingly and willingly killing another person or helping $\mathrm{him} /$ her to do so is everything but a normal (medical) act," (Broeckaert 2011, 64) and by Robinson, who opines that PAS is "facilitating an act that is no part of medical science or of the healing arts" (Robinson 2010, 15).

Arguments against euthanasia have been based on the moral wrong of killing in and of itself, as well as the "slippery slope" argument that those who are judged to have less utility in society (the elderly, the disabled, racial minorities) would be more vulnerable to being euthanized (Battin 2004, 2481). This issue of euthanasia in vulnerable populations is foreboding. In Oregon, fewer psychiatric consultations are being done to evaluate prospective PAS patients for depression, raising the possibility that reversible mental disorders may be playing a factor in these requests (Van Norman 2014, 178). In the Netherlands, a number of patients undergo euthanasia without an explicit request and 20 percent of cases go unreported, both raising questions of whether legal standards are being met (Van Norman 2014, 178). Callahan details this more specifically: 2 percent of Dutch deaths (some 3,500) resulted from euthanasia or PAS, and 1,000 of these were without explicit request, while fewer than the 45 percent required by law were reported (Callahan 2008, 31).

In contrast to euthanasia or PAS is the practice of palliative sedation. Broeckaert defines palliative sedation as

\section{the intentional administration of sedative drugs and combinations required to reduce the consciousness of a terminal patient as much as necessary to ade- quately relieve one or more refractory symptoms. (Broeckaert 2011, 64)}

Thus it is clear that the intent, unlike in euthanasia and PAS, is not on ending life, but on relieving symptoms. A study of advanced cancer patients yielded the principal reason for palliative sedation to be agitated delirium, with dyspnea (shortness of breath) being the second most common indication; both healthcare professionals and relatives caring for the sick person expressed satisfaction with the experience of palliative sedation (Mercadante et al. 2014, 860).

\section{The role of suffering in end-of-life care}

Although the compassionate healthcare professional always attempts to alleviate suffering to the best of his or her ability, there exists a danger in making the avoidance of suffering at all costs an ultimate goal. A further question is thus raised: Is there any meaning to be gained from suffering?

Suffering may reveal a "greater depth of human experience and meaning" and 
a richer understanding of the meaning of being human, a greater concern for the suffering of others, and away from the superficialities that too often characterize daily existence. (Cassell 2004, 1967)

This interpretation may be of value even for the non-religious patient. For a patient with a more religious orientation, commentary of the Church fathers sheds light on how this judgment may be seen in scripture. Gregory the Great, commenting on the Book of Job, says one may grow from grief and wickedness to temporal greatness (Simonetti and Conti 2004, 23); and John Chrysostom, commenting on the story of the man born blind in John 9:3, emphasizes the aspect that "the man was made to suffer so that God's glory might be revealed in him" (Elowsky 2004, 321).

Continuing with this perspective, the acceptance of a higher meaning potentially to be gained from suffering necessitates an attitude of patience as well as the humility of acceptance of our human limitations in the face of a loving and caring God. Cyril of Alexandria, in commenting on the same passage in John states, "there are certain wondrous things that God alone understands" and that

since God is the fountain of all righteousness, God will neither do nor determine anything whatsoever in human affairs or in those of the rest of creation that is unbecoming to God. (Elowsky 2004, 321)

Humility is essential in accepting a limited understanding of suffering. Augustine, in commenting on the parable of the fig tree in Luke 13:6-9, emphasized the mercy of leaving rather than cutting down the fig tree and applying a load of manure to it in the hope that it might bear fruit (Just 2004, 223). Similarly, the one who suffers from terminal disease may find reconciliation in one's waning days with estranged loved ones, aided by the humility that is brought about by the limitations imposed by that suffering. Tertullian, in commenting on the notion that "the Lord reproves him who he loves" found in Proverbs $3: 11-12$, says,

If we believe some blow of misfortune is struck by God, to whom would it be better that we manifest patience than to our Lord? (Wright 2004, 23)

Would it seem then that one who believes in God or a higher purpose might perhaps be better equipped to deal with what otherwise might be a meaningless exercise? Such a person might hold truths that have

the capacity for transforming character and relieving suffering when they are sincerely held and vividly apprehended, even in the painful void of evidence for their truth. (Cassell 2004, 1967)

Guroian adds an Eastern Christian perspective to this, opining that "Christian love is possible only after pride "is replaced by the humility of Jesus Christ"' (Guroian 2002, 82).

\section{The value of palliative care}

It is often believed that palliative care medicine is "synonymous with end-of-life care or as being what we do when there is nothing more that we can do," but this is falsely predicated on medical care being "understood to have two mutually exclusive goals: to cure disease and prolong life or to provide comfort care" (Meier and Brawley 2011, 2750). Palliative medical care is in fact best instituted early in the course of a cancer patient's treatment as

prolonged stressors associated with serious illness diminish immune reserve and ... psychosocial, symptom, and other quality-of-life interventions provided by palliative care might disrupt this pathway and lead to improved outcomes. (Meier and Brawley 2011, 2750) 
Further supporting this, a study carried out at an academic medical center oncology service showed that an unscheduled hospital admission for a patient with advanced cancer correlated with a survival of less than 6 months and that such unscheduled hospitalizations might therefore trigger hospice eligibility and commencement of end-of-life planning, leading these authors to initiate palliative care consultation for all inpatients on their solid tumor service (Rocque et al. 2013, 53).

If such a transfer of care is effected, it is important for the referring oncologist to remain active in the patient's care. There exists a trust between the cancer patient and his or her oncologist, and it may be best that hospice be seen as an adjunct rather than a replacement of oncologic care lest the patient feel abandoned by such a transfer (Simon and Kodish 2004, 347).

It appears that this change in thinking regarding end-of-life care is beginning to take a foothold. By way of perspective, the first hospice program in the United States began in 1974, and Medicare patients over 65 could begin receiving hospice benefit in 1983; now in the interval from 1982 to 2000 , the number of providers of such care increased from 500 to 3,100, while between 1975 and 2000 the patient population served grew from roughly 1,000 to 700,000 (Doyle and Barnard 2004, 1972). In Great Britain, the number of palliative medicine specialists now exceeds the number of oncologists (Doyle and Barnard 2004, 1972).

The role of adequate pain control remains paramount in the provision of end-of-life palliative care, particularly in cancer patients. It is beneficial, and this is the case at the medical center where this author practices, when there exists a collaborative relationship between the pain medicine service and the palliative care service. There has been found to be a prevalence of pain in cancer survivors of 33 percent, in cancer patients undergoing active treatment of 59 percent, and across all stages of cancer of 53 percent (Meier and Brawley 2011, 2750). A survey of primary reasons for admission to an inpatient oncology service showed poor symptom control to be responsible for 66 percent of such admissions, nearly one-third of which were due to uncontrolled or poorly controlled pain (Rocque et al. 2013, 52).

The specialty of pain medicine, although relatively new on the medical landscape, offers fellowship-trained physicians with considerable expertise. Such practitioners may make use of sophisticated pharmacologic analgesic regimens, nerve blocks performed with radiologic imaging, and even surgical implantation of neuromodulation technologies such as spinal cord stimulation, peripheral nerve stimulation, and intrathecal opioid and adjuvant analgesic delivery devices. Such consultative services may be provided at the behest of a primary-care physician, internist, or oncologist challenged with control of a patient's cancer pain, even in end-of-life situations.

An interesting insight into the spiritual dimension of a physician's care for end-of-life patients was recently illuminated. Thirty-nine percent of Belgian physicians surveyed had received a request for euthanasia from a patient, and the physician characteristics most associated with receiving such a request were caring for a high number of terminally ill patients, having experience in palliative care, and, interestingly, not being religious (Van Wesemael et al. 2011, 730).

Thus the role of the physician is significant. Basil of Caesarea, in his fourth-century epistle to the court physician Eustathius tells him that "your profession is the supply vein of health" (Harakas 2004, 693, 691-7). James Drane elucidates this concept further and even applies it to the non-religious patient, saying that "for the many modern persons of our secular society who are neither true 
atheists nor persons practicing religion, the doctor may be the only source of help during a period of painful doubt," (Drane 1988, 125) and further expands:

The doctor who is sensitive to all of the dimensions of his patient's needs may be the best person to accompany a patient through the dying process. People who lived without religion will likely die without benefit of clergy. But since most people have 'religious' needs at this time, the doctor may be the most indicated professional to help. (Drane 1988, 125)

Drane goes on to conclude that a certain level of spirituality is a sine qua non for a true physician:

Some doctors, themselves secular persons, feel helpless in the face of death and regularly flee to more medically hopeful cases. But doctors who aspire to be good by trying to meet all the patient's needs have to reconsider what, to a contemporary secular physician, may seem preposterous: i.e., a joining of medicine and religion. (Drane 1988, 127)

The acceptance of a spiritual role by the physician in this process might therefore lead to a re-interpretation of how society approaches the dilemma of suffering in end-of-life care.

\section{A larger view of life and health}

An Eastern Christian ethos calls for "a healthy mind and a healthy spirit with a healthy body," and considers the body to be "neither merely an instrument nor simply a dwelling place of the spirit" but a "constituent part of human existence" (Harakas 2004, 693, 691-7). Although the practice of $\alpha \sigma \kappa \varepsilon \sigma \mathrm{s} \varsigma$ (from which the concept of asceticism is derived) looks to place the body under the control of the mind and the spirit, Harakas makes it clear that this is "never to be understood as a dualistic condemnation of the body," and that "Practices that contribute to bodily health and well-being are ethically required" (Harakas 2004, 693, 691-7).

What appears to be crucial in an examination of the validity or lack thereof of a culture that allows or supports PAS is to discern the mentality from which that support springs. Stanley Hauerwas and Richard Bondi speak poignantly to this issue saying that,

suicide and euthanasia are properly seen not as forms of death but as the outcome of certain attitudes toward life. For the Christian the reasons for living begin with the understanding that life is a gift. (Hauerwas and Bondi 1976, 445)

This perspective may be shared by other value and belief systems. This gift, however, is not simply to be disposed of at the whim of the recipient, for "this is a gift that is not a property to possess" but rather "a task to live out, a task where freedom follows upon responsibility" (Hauerwas and Bondi 1976, 445). It thus may become imperative to embrace a paradigm shift that ensues by recognizing in humility one's place as a creature of God or a higher power. Hauerwas and Bondi continue:

We are not our own creators. Our desire to live should be given shape in the affirmation that we are not the determiners of our life, but God is. We Christians are people who must learn to live as we have learned that life is a gift. We thus live not as if survival is an end in itself, but rather because we know that life allows us the time and space to live in the service of God. (Hauerwas and Bondi 1976, 445)

One may actualize this concept of accepting life as a gift and embrace the role as a created being by the practice of compassion toward the dying. The Church Father Ambrose puts it plainly: "It is a noble thing to do one's kindnesses and duties toward the whole of the human race" (Lienhard 2004, 284). Guroian expands on this in commenting on the parable of the Good Samaritan: 
To act with compassion toward another human being is to recognize the human worth of the other on the affective level of empathy. It is the first step toward befriending and knowing that person in God. (Guroian 2002, 82)

Much of the burden incumbent upon one suffering from terminal disease must be borne by the family, and the role for compassion and support as such is crucial. David Gushee makes an assertion against euthanasia by calling on the family's role, imploring that,

a good and loving family ... will find some way to show its compassion to the sick and suffering that does not involve directly taking their lives. (Gushee 2004, 62)

This responsibility of caring for the dying extends to the greater society as well, in an effort to bring about

values, practices, and institutions that will assure each of us the sort of care - familial, societal, and medical - that will make the resort to assistance in suicide unnecessary. (Robinson 2010, 15)

Just as the community may witness to the dying, the dying may also witness to the community, an often-neglected aspect of this economy between the two. Suicide, whether autonomous or physician-assisted, has been judged by Hauerwas and Bondi to be a form of "moral manipulation, as it abandons those left behind to their shame, guilt and grief," and instead imputes that terminal illness is something

we should be willing to bear for the good and with the aid of the community - so we will not put our friends and lovers in the position of having to kill us. (Hauerwas and Bondi 1976, 445)

Harakas sums up an alternative approach to euthanasia or PAS in saying that although "suffering should be relieved as much as possible," "Death should come of itself, without human intervention. God gives us life; God should be allowed to take it away" (Harakas 2004, 693, 691-7).

\section{Conclusion}

The argument in favor of euthanasia or PAS in end-of-life cancer care appears ostensibly compassionate and practical. Further examination reveals this stance to be ultimately predicated on a platform which seems to fail to consider wellfounded alternatives, and additionally to deny the fundamental existence of humans as created beings. The alternative approach of the appropriate use of the specialty of pain medicine within a greater setting of palliative care allows compassionate care and fundamental respect for the dying as those having human lives of value. Although suffering is to be eased whenever possible, the presence of healthcare practitioners with a spiritual orientation may lead to less likelihood that this goal will be attempted to be accomplished at the expense of all else, especially the life of the patient.

\section{Acknowledgment}

The author would like to extend his thanks to Tom L. Beauchamp, Ph.D., for thoughtful review of the manuscript.

\section{REFERENCES}

Battin, Margaret Pabst. 2004. Suicide. In Encyclopedia of bioethics, vol. 4, ed. Stephen G. Post, 2475-83. New York: Macmillan Reference USA.

Broeckaert, Bert. 2011. Palliative sedation, physician-assisted suicide, and euthanasia: "Same, same, but different"? American Journal of Bioethics 11: 62-64.

Callahan, Daniel. 2008. Organized obfuscation: Advocacy for physician-assisted suicide. Hastings Center Report 38 (5): 30-32.

Cassell, Eric J. 2004. Pain and suffering. In Encyclopedia of bioetbics, vol. 4, ed. Stephen 
G. Post, 1961-9. New York: Macmillan Reference USA.

Drane, James F. 1988. Becoming a good doctor: The place of virtue and character in medical ethics. Kansas City, MO: Sheed \& Ward.

Doyle, Derek, and David Barnard. 2004. Palliative care and hospice. In Encyclopedia of bioetbics, vol. 4, ed. Stephen G. Post, 196975. New York: Macmillan Reference USA.

Elowsky, Joel. 2004. John. Ancient Christian commentary on scripture. Downers Grove, IL: InterVarsity Press.

Guroian, Vigen. 2002. Incarnate love: Essays in orthodox ethics. 2nd ed. Notre Dame, IN: University of Notre Dame Press.

Gushee, David P. 2004. Killing with kindness. Christianity Today 48: 62.

Harakas, Stanley. 2004. Bioethics in Eastern Orthodox Christianity. In Encyclopedia of bioethics, Vol. 1, ed. Stephen G. Post. New York: Macmillan Reference USA.

Hauerwas, Stanley, and Richard Bondi. 1976. Memory, community and the reasons for living: Theological and ethical reflections on suicide and euthanasia. Journal of the American Academy of Religion 44: 439-52.

Just, Arthur A. 2004. Luke. Ancient Christian commentary on scripture. Downers Grove, IL: InterVarsity Press.

Lienhard, Joseph T., S.J. 2004. Exodus, Leviticus, Numbers, Deuteronomy. Ancient Christian commentary on scripture. Downers Grove, IL: InterVarsity Press.

Meier, Diane E., and Otis W. Brawley. 2011. Palliative care and the quality of life. Journal of Clinical Oncology 29: 2750-2.

Mercadante, Sebastiano, Giampiero Porzio, Alessandro Valle, Federica Aielli, and Alessandra Casuccio. 2014. Palliative sedation in patients with advanced cancer followed at home: A prospective study. Journal of Pain and Symptom Management 47: 860-6.

Robinson, John. 2010. Baxter and the return of physician-assisted suicide. Hastings Center Report 40 (6): 15-17.

Rocque, Gabrielle B., Anne E. Barnett, Lisa C. Illig, Jens C. Eickhoff, Howard H. Bailey, Toby C. Campbell, James A. Stewart, and James F. Cleary. 2013. Inpatient hospitalization of oncology patients: Are we missing an opportunity for end-of-life care? Journal of Oncology Practice 9: 51-54.
Ruijs, Cees D.M., J.F.M. Ad, Gerrit Kerkhof, Bregje D. van der Waal, and Onwuteaka-Philipsen. 2013. Symptoms, unbearability and the nature of suffering in terminal cancer patients dying at home: A prospective primary care study. $B M C$ Family Practice 14 (201): 1-17.

Simon, Christian M., and Eric D. Kodish. 2004. Cancer, ethical issues related to diagnosis and treatment. In Encyclopedia of bioethics, vol. 1, ed. Stephen G. Post, 3419. New York: Macmillan Reference USA.

Simonetti Manlio, and Marco Conti. 2004. Job. Ancient Christian commentary on scripture. Downers Grove, IL: InterVarsity Press.

Van Norman, Gail A. 2014. Physician aid-in-dying: Cautionary words. Current Opinions in Anesthesiology 27: 177-82.

Van Wesemael Yanna, Joachim Cohen, Johan Bilsen, Tinne Smets, Bregje Onwuteaka-Philipsen, and Luc Deliens. 2011. Process and outcomes of euthanasia requests under the Belgian act on euthanasia: A nationwide survey. Journal of Pain and Symptom Management 42: 721-33. Wright, J. Robert. 2004. Proverbs, Ecclesiastes, Song of Solomon. Ancient Christian commentary on scripture. Downers Grove, IL: InterVarsity Press.

\section{Biographical Note}

Michael Erdek M.D., is associate professor of anesthesiology and critical care medicine and oncology at the Johns Hopkins University School of Medicine. Dr. Erdek received his undergraduate medical education at the University of Pennsylvania. He trained in surgery and in anesthesiology prior to completing his subspecialty training in pain medicine and critical care medicine at the Johns Hopkins University. Dr. Erdek has been appointed to the Polyanalgesic Consensus Panel, which formulates international recommendations for intraspinal drug delivery. $\mathrm{He}$ is a member of the editorial board of several journals in the field of pain medicine. His email address is merdek@jhmi.edu. 